\title{
Gemstone spectral imaging for measuring adult bone mineral density
}

\author{
WEI-GUANG SHAO and DIAN-MEI LIU \\ Imaging Center, The Affiliated Hospital of Weifang Medical University, Weifang, Shandong 261031, P.R. China
}

Received May 7, 2015; Accepted June 14, 2016

DOI: $10.3892 /$ etm.2016.3652

\begin{abstract}
The present study aimed to detect the bone $\mathrm{Ca}^{2+}$ content of L3 vertebrae in adults by gemstone spectral computed tomography. In total, 235 patients were selected and divided into age groups of 10 years each. The scanning data were used to detect the water-based and $\mathrm{Ca}^{2+}$-based substance levels on the L3 vertebral cancellous bone images. The results indicated that there were significant differences in vertebral $\mathrm{Ca}^{2+}$-water and water- $\mathrm{Ca}^{2+}$ densities determined by gemstone spectral imaging (GSI) between males and females in subjects aged 50-59 years, 60-69 years, 70-79 years and $\geq 80$ years $(\mathrm{P}<0.05)$. The ages of male and female participants were negatively correlated with vertebral $\mathrm{Ca}^{2+}$-water density $(\mathrm{P}<0.01)$ and water- $\mathrm{Ca}^{2+}$ density $(\mathrm{P}<0.01)$. In conclusion, GSI may be used as a novel method of measuring the vertebral adult bone mineral density.
\end{abstract}

\section{Introduction}

Osteoporosis is a considered to be one of the most common diseases and public health problems $(1,2)$. Spinal compression fractures and hip fractures are easily caused in individuals with osteoporosis, thus severely affecting the health of older individuals. Along with the gradual increase in the aging population, the medical community is increasingly concerned about this widely existing systemic bone disease $(3,4)$. The early diagnosis and prevention of osteoporosis is of great importance, and detecting the bone mineral density (BMD) is the most commonly used clinical method of diagnosis $(5,6)$. Currently, dual-energy X-ray absorptiometry (DXA) is recognized as the gold standard for measuring $\operatorname{BMD}(7,8)$; however, the results of BMD provide the sum of minerals in the cortical and cancellous bones, and thus early detection of osteoporosis originating from the vertebral cancellous bone

Correspondence to: Professor Dian-Mei Liu, Imaging Center, The Affiliated Hospital of Weifang Medical University, 465 Yuhe Road, Weifang, Shandong 261031, P.R. China

E-mail: dianmeiliu@126.com

Key words: spectral imaging, X-ray, computed tomography, bone mineral density is difficult $(9,10)$. Conventional computed tomography (CT) examination of osteoporosis typically depends on the clinicians experience in detecting trabecular bone rarefraction, vertebral double-concave deformation and density decreases, which cannot accurately reflect the alteration in BMD; therefore, dual-energy quantitative CT may theoretically be the best technique for measuring BMD (11). It has previously been demonstrated that the $\mathrm{Ca}^{2+}$-water and water- $\mathrm{Ca}^{2+}$ densities can be used for diagnosing osteoporosis and calculating the BMD (12). Gemstone spectral CT (GSCT) uses single-energy transient $\mathrm{kVp}$ switching technology to capture images of material densities, thus obtaining $\mathrm{Ca}^{2+}$-based and water-based images that reflect the bone mineral content and changes in the content via the $\mathrm{Ca}^{2+}$-water and water- $\mathrm{Ca}^{2+}$ densities $(12,13)$.

The present study used $\mathrm{Ca}^{2+}$-based gemstone spectral imaging (GSI) to measure the L3 vertebral $\mathrm{Ca}^{2+}$-water densities and water-based imaging to measure the L3 vertebral water- $\mathrm{Ca}^{2+}$ densities in 235 subjects. The study aimed to compare the association of gender and age with the GSI-measured $\mathrm{Ca}^{2+}$-water and water- $\mathrm{Ca}^{2+}$ densities, and to examine the feasibility of GSI technology in measuring the BMD.

\section{Materials and methods}

General information. A total of 235 patients with osteoporosis who underwent abdominal or lumbar GSI at the Affiliated Hospital of Weifang Medical University (Weifang, China) between May 2012 and May 2013 were enrolled into the present study, including 113 males and 122 females. The study was conducted in accordance with the Declaration of Helsinki, and was confirmed and approved by the hospital's Ethical Committee. Signed informed consent was obtained from all patients.

The selected patients had no history of cancer, spinal trauma, surgery and other diseases that may affect the BMD, including hyperthyroidism, hyperparathyroidism, diabetes, congenital osteoarthrosis, sequelae of cerebrovascular disease, immune dysfunction, long-term administration of corticosteroids, and liver, kidney or rheumatic diseases. The patients were aged between 20 and 87 years, with a mean age of 50.6 \pm 8.2 years. The patients were divided into seven age groups of 10 years each, as follows: Group 1, 20-29 years; group 2, 30-39 years; group 3, 40-49 years; group 4, 50-59 years; group 5, 60-69 years; group 6, 70-79 years; and group 7, $\geq 80$ years. 
CT imaging technique. A Discovery CT750 HD spectral CT scanner (GE Healthcare, Waukesha, WI, USA) was used in the present study. The L3 vertebral bodies of all patients were subjected to GSI with the following scanning conditions: Instantaneous switching, $80-140 \mathrm{kVp}$; automatic mAs; slice thickness, $5 \mathrm{~mm}$; spacing, $5 \mathrm{~mm}$; pitch, 0.984; speed, $39.37 \mathrm{~mm} /$ cycle; and rotation time, $0.8 \mathrm{sec} /$ rotation.

Image post-processing and density measurement. The single-energy image, with a slice thickness of $0.625 \mathrm{~mm}$, was reconstructed and transmitted to the Advantage Workstation version 4.4 (GE Healthcare) for processing with GSI Viewer (GE Healthcare). The $\mathrm{Ca}^{2+}$-water-based (Fig. 1) and water- $\mathrm{Ca}^{2+}$-based (Fig. 2) material images were thus obtained, and the $\mathrm{Ca}^{2+}$-water and water- $\mathrm{Ca}^{2+}$ densities of the region of interest (ROI) were measured on the L3 vertebral cancellous bone level, and the mean value was then obtained. When selecting the ROI, the entire cancellous bone was maximally covered, and the region was $\sim 5 \mathrm{~mm}$ to the cortical edge in order to avoid any bone islands and venous plexuses. In all cases, the size of the ROI was $\sim 300 \mathrm{~mm}^{2}$.

Statistical analysis. SPSS version 13.0 software package (SPSS, Inc., Chicago, IL, USA) was used for statistical analysis. One-way analysis of variance was performed for the statistical processing of measurement data. The association of age with the vertebral GSI-obtained $\mathrm{Ca}^{2+}$-water and water- $\mathrm{Ca}^{2+}$ densities was investigated with Pearson correlation analysis. In addition, intergroup differences between the male and female groups were investigated by Student's t-test. $\mathrm{P}<0.05$ was considered to indicate a statistical significant difference.

\section{Results}

Specific values of L3 vertebral GSI-determined $\mathrm{Ca}^{2+}$-water and water- $\mathrm{Ca}^{2+}$ densities of all age groups. The highest vertebral $\mathrm{Ca}^{2+}$-water and water- $\mathrm{Ca}^{2+}$ density determined by GSI was observed in the 20-29 year-old group in males and in the 30-39 year-old group in females (Tables I and II). The vertebral $\mathrm{Ca}^{2+}$-water density determined by GSI in males aged 20-29 years old was $79.4012 \pm 7.8896 \mathrm{mg} / \mathrm{cm}^{3}$, which was the highest among all groups; the vertebral $\mathrm{Ca}^{2+}$-water density in females aged 30-39 years old was $80.6257 \pm 8.6175 \mathrm{mg} / \mathrm{cm}^{3}$, which was the highest among all groups (Table I). The vertebral water- $\mathrm{Ca}^{2+}$ density in males aged 20-29 years old was $1,024.1680 \pm 7.5345 \mathrm{mg} / \mathrm{cm}^{3}$, which was the highest among all the groups. The vertebral water- $\mathrm{Ca}^{2+}$ density in females aged $30-39$ years old was $1,028.3190 \pm 10.3976 \mathrm{mg} / \mathrm{cm}^{3}$, which was the highest among all the groups (Table II).

Comparison of $\mathrm{Ca}^{2+}$-water and $\mathrm{Ca}^{2+}$-water densities in males and females. The vertebral $\mathrm{Ca}^{2+}$-water densities determined by GSI in age groups 1-3 showed no statistically significant differences between males and females, with $t$ values of $-0.283,-1.625$ and 1.685 , respectively (all $\mathrm{P}>0.05$ ). By contrast, the $\mathrm{Ca}^{2+}$-water densities of individuals in age groups 4-7 demonstrated statistically significant differences between males and females (group 4: $\mathrm{t}=4.512, \mathrm{P}<0.001$; group 5: $\mathrm{t}=10.632, \mathrm{P}<0.001$; group 6: $\mathrm{t}=5.346, \mathrm{P}<0.001$; group 7: $\mathrm{t}=2.511, \mathrm{P}=0.029$ ) (Table I). Furthermore, the vertebral GSI-determined water- $\mathrm{Ca}^{2+}$ densities in all age groups were not found to be significantly different between males and females (Table II).

Correlation of age and gender with $\mathrm{Ca}^{2+}$-water and water- $\mathrm{Ca}^{2+}$ densities. As shown in Fig. 3, the male participants exhibited a decreasing trend in vertebral GSI-determined $\mathrm{Ca}^{2+}$-water density with increasing age $(\mathrm{r}=-0.6815$; $\mathrm{P}<0.01)$; whereas females aged $\geq 40$ years presented a decreasing trend in $\mathrm{Ca}^{2+}$-water density with increasing age $(\mathrm{r}=-0.7961 ; \mathrm{P}<0.01)$. Females age $\leq 39$ years exhibited no significant correlation between age and $\mathrm{Ca}^{2+}$-water density $(\mathrm{r}=0.1901 ; \mathrm{P}=0.3735)$. As shown in Fig. 4, males aged $\geq 40$ years exhibited a decreasing trend in water- $\mathrm{Ca}^{2+}$ density with increasing age ( $\mathrm{r}=-0.9065$; $\mathrm{P}<0.01$ ); whereas females aged $\leq 70$ years demonstrated a decreasing trend in water- $\mathrm{Ca}^{2+}$ density with increasing age $(\mathrm{r}=-0.8877 ; \mathrm{P}<0.01)$. Males aged $\leq 39$ years $(\mathrm{r}=-0.0233$; $\mathrm{P}=0.9140)$ and females aged $\geq 71$ years $(\mathrm{r}=-0.0432 ; \mathrm{P}=0.5632)$ exhibited no significant correlation between their age and water- $\mathrm{Ca}^{2+}$ density.

\section{Discussion}

Osteoporosis, which refers to the reduction of bone mass per unit volume, is a disease that is closely associated with age. BMD detection is an important means for the early diagnosis and evaluation of osteoporosis. Since the lumbar spine is the most common site involved in the early stages of osteoporosis, BMD measurement is typically performed at the lumbar spine region (14). Currently, lumbar spinal BMD detection using the DXA and quantitative CT methods remains the best technique to diagnose and evaluate osteoporosis $(14,15)$. In particular, use of the DXA method has been recommended by the World Health Organization as part of the diagnostic criteria for osteoporosis $(14,16)$; however, this method has certain limitations, since it is unable to distinguish between the cancellous and the cortical bones. Due to the different conversion rates of cortical and cancellous bones, alterations in the bone during early osteoporosis initially occur in the cancellous bone. This is due to the large surface area and high metabolic conversion rate of the cancellous bone, which were greater than those in the cortical bone. Thus, the DXA method may not detect early osteoporosis originating from the vertebral cancellous bone, and may reduce the sensitivities of osteoporosis towards treatment (17). In addition, detection from the posteroanterior lumbar may only obtain the area density within that region, which also includes images of surrounding structures such as accessories, paraspinal ligaments and abdominal aorta other than the lumbar vertebrae; therefore, this detection technique would be greatly affected by the osteosclerotic images of hyperostosis, which may lead to the distortion of measurement data to a certain extent (18).

Quantitative CT can be used to measure the actual volumetric BMD, completely ruling out the effects of bone size, while it can also measure the densities of the cortical and cancellous bones, as well as more accurately determine the morphological parameters. Therefore, measurements by quantitative CT may be able to reflect the early changes in vertebral bone mass. However, a limitation of this method is 
Table I. $\mathrm{Ca}^{2+}$-water densities of L3 vertebrae, as determined by gemstone spectral imaging, and statistical analysis in the various age groups.

\begin{tabular}{|c|c|c|c|c|c|c|}
\hline \multirow{2}{*}{$\begin{array}{l}\text { Age group } \\
\text { (years) }\end{array}$} & \multirow{2}{*}{$\begin{array}{c}\text { No. of } \\
\text { males }\end{array}$} & \multirow{2}{*}{$\begin{array}{l}\text { No. of } \\
\text { females }\end{array}$} & \multicolumn{2}{|c|}{$\mathrm{Ca}^{2+}$-water density $\left(\mathrm{mg} / \mathrm{cm}^{3}\right)$} & \multicolumn{2}{|c|}{ t-test } \\
\hline & & & Males $(n=113)$ & Females $(\mathrm{n}=122)$ & $\mathrm{t}$-value & P-value \\
\hline $20-29$ & 17 & 15 & $79.4012 \pm 7.8896$ & $80.3740 \pm 9.8189$ & -0.283 & 0.780 \\
\hline $30-39$ & 15 & 18 & $75.4280 \pm 8.5935$ & $80.6257 \pm 8.6175$ & -1.625 & 0.116 \\
\hline $40-49$ & 19 & 22 & $67.9171 \pm 8.2366$ & $63.2672 \pm 8.9045$ & 1.685 & 0.100 \\
\hline $50-59$ & 23 & 25 & $63.2400 \pm 4.6890$ & $51.7106 \pm 8.1675$ & 4.512 & $<0.001$ \\
\hline $60-69$ & 15 & 15 & $51.7440 \pm 4.4829$ & $35.8400 \pm 3.6696$ & 10.632 & $<0.001$ \\
\hline $70-79$ & 13 & 14 & $43.8656 \pm 4.4570$ & $29.2200 \pm 6.9053$ & 5.346 & $<0.001$ \\
\hline$\geq 80$ & 11 & 13 & $33.9017 \pm 6.7504$ & $25.8386 \pm 4.8065$ & 2.511 & 0.029 \\
\hline
\end{tabular}

Table II. Water-Ca ${ }^{2+}$ densities of L3 vertebrae, as determined by gemstone spectral imaging, and statistical analysis in the various age groups.

\begin{tabular}{lccccrrr}
\hline \multirow{2}{*}{$\begin{array}{l}\text { Age group } \\
\text { (years) }\end{array}$} & $\begin{array}{c}\text { No. of } \\
\text { males }\end{array}$ & $\begin{array}{c}\text { No. of } \\
\text { females }\end{array}$ & & \multicolumn{2}{c}{ Water-Ca $\mathrm{Ca}^{2+}$ density $\left(\mathrm{mg} / \mathrm{cm}^{3}\right)$} & & \multicolumn{2}{c}{ t-test } \\
\cline { 5 - 7 } \cline { 5 - 7 } & 17 & 15 & $1,024.1680 \pm 7.5345$ & $1,021.4307 \pm 16.9910$ & -1.599 & 0.122 \\
$30-39$ & 15 & 18 & $1,019.9606 \pm 14.4219$ & $1,028.3190 \pm 10.3976$ & 0.567 & 0.575 \\
$40-49$ & 19 & 22 & $1,009.3271 \pm 8.7338$ & $1,014.9172 \pm 9.7994$ & -1.866 & 0.070 \\
$50-59$ & 23 & 25 & $1,003.2423 \pm 17.4680$ & $999.9331 \pm 14.3856$ & 0.560 & 0.580 \\
$60-69$ & 15 & 15 & $1,001.4167 \pm 13.7474$ & $989.4767 \pm 9.4838$ & 1.769 & 0.135 \\
$70-79$ & 13 & 14 & $987.4067 \pm 14.3953$ & $980.0378 \pm 11.7370$ & 1.190 & 0.251 \\
$\geq 80$ & 11 & 13 & $984.0467 \pm 6.3942$ & $982.7571 \pm 6.4488$ & & 0.361 & 0.725 \\
\hline
\end{tabular}

that it requires a dedicated phantom and specialized software for bone density measurement and analysis $(19,20)$. Since each manufacturer has different operating and preparing standards for the phantom, the measurement results of operating phantoms may present various uncertainties, while the method is more complex and requires a higher dose of radiation compared with other techniques; therefore, the widespread clinical applications of quantitative CT are limited (21).

Theoretically, the ideal technique for BMD measurement would be dual-energy CT scanning. However, this method requires duplicated scanning, and is thus limited by image mismatching and high radiation doses; in addition, it is a complicated technique with no corresponding software available, therefore limiting its clinical applications (22). GSCT is another technique that can achieve spectral imaging by instant switching of dual energy through a single bulb, using unique technologies of physical separation and quantitative determination of the material density, measuring the $\mathrm{Ca}^{2+}$-water and water- $\mathrm{Ca}^{2+}$ densities of the vertebral cancellous bone.

The absorption of objects results in changes in X-ray energy, and during the application of two X-ray energy spectra, the $\mathrm{X}$-ray attenuation is altered. The base materials in any tissue have different absorption proportions towards X-ray, and their combinations represent the X-ray attenuation (23).

The base materials may not necessarily be the actual substances contained in the tissue, as they simply represent the
X-ray attenuation of this tissue; the measurement of matched base materials may reflect the relative contents of these substances in the tissue (24). The main components of vertebral cancellous bone are bone minerals (such as $\mathrm{Ca}^{2+}$ salt), water and collagen; therefore, water- $\mathrm{Ca}^{2+}$ or $\mathrm{Ca}^{2+}$-water-based substances may pair up and indirectly reflect the $\mathrm{Ca}^{2+}$ content and changes in the cancellous bone.

In the present study, GSCT was used to measure the $\mathrm{Ca}^{2+}$-water densities of L3 vertebral cancellous bone among different age groups. The results demonstrated that the highest GSI-determined $\mathrm{Ca}^{2+}$-water density was observed in males with ages of 20-29 years and females with ages of 30-39 years, suggesting that the BMD peak in male and female vertebral cancellous bones was reached at different ages. In addition, the results indicated that the age of male participants was negatively correlated with vertebral GSI-determined $\mathrm{Ca}^{2+}$-water densities, suggesting that the male vertebral $\mathrm{Ca}^{2+}$ contents decreased with increasing age. In females $\leq 39$-years-old, the GSI-determined $\mathrm{Ca}^{2+}$-water density of vertebral cancellous bone was slightly elevated with increasing age, but there was not statistically significant correlation between the age and vertebral $\mathrm{Ca}^{2+}$-water densities. By contrast, females $\geq 40$-years-old presented a negative correlation between age and vertebral GSI-determined $\mathrm{Ca}^{2+}$-water densities, suggesting a gradual decrease in vertebral $\mathrm{Ca}^{2+}$ content from 40 years of age. Furthermore, the results of the current study 


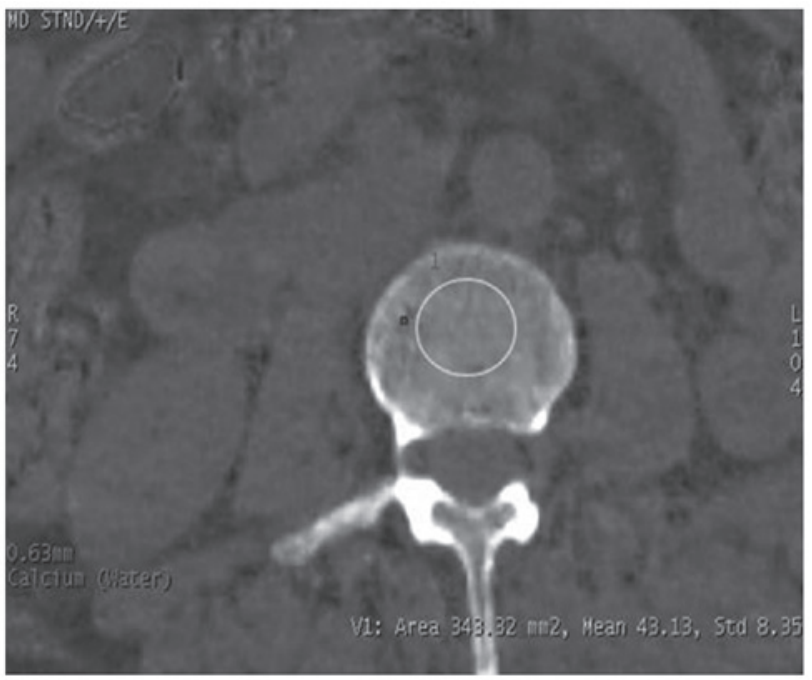

Figure 1. Representative case of a 52-year-old female. The L3 vertebral $\mathrm{Ca}^{2+}$-water density was $43.13 \mathrm{mg} / \mathrm{cm}^{3}$, as determined by gemstone spectral imaging.

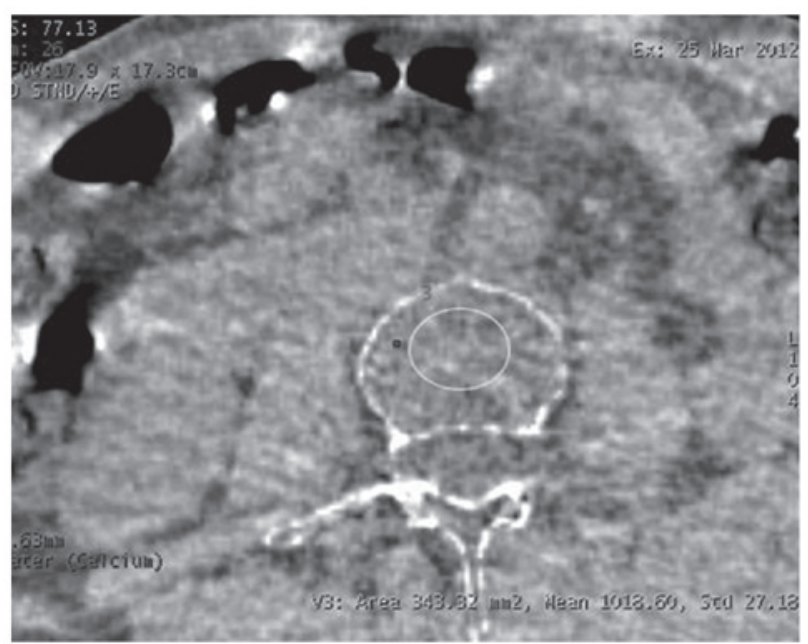

Figure 2. Representative case of a 52-year-old female. The L3 vertebral water- $\mathrm{Ca}^{2+}$ density was $1,018.60 \mathrm{mg} / \mathrm{cm}^{3}$, as determined by gemstone spectral imaging.

revealed that the $\mathrm{Ca}^{2+}$ content began to decrease at a later age in females compared with males, and the reason behind this trend requires further investigation. Regarding the slight difference in the ages at which the peak BMD of vertebral cancellous bone appeared in males and females, which was also reported in a previous study (25), we hypothesize that it may be associated with the separative statistics of males and females, and the numbers of selected cases. Before 40 years of age, the GSI-determined $\mathrm{Ca}^{2+}$-water density of the vertebral cancellous bone in females was significantly higher compared with that in males within the same age period; however, after 50 years of age, this density was significantly reduced in females compared with that in males, and the difference was statistically significant $(\mathrm{P}<0.01)$, which is consistent with numerous previous studies $(26,27)$. This trend may be caused by the decline of estrogen in females $>50$-years-old, resulting in reduced vertebral $\mathrm{Ca}^{2+}$ content (27). Furthermore, lactation,

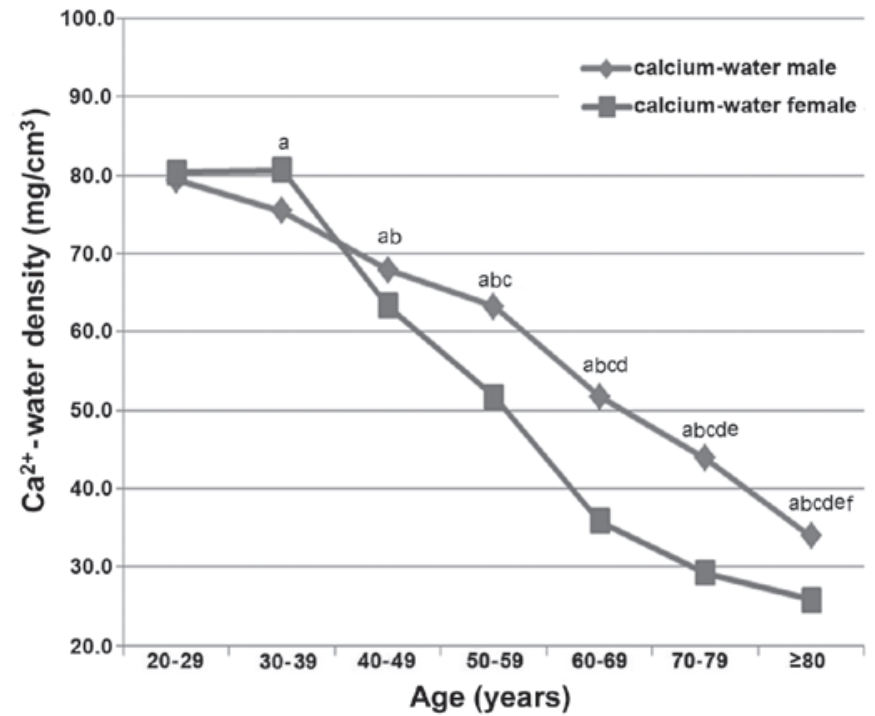

Figure 3. Correlation curves of vertebral $\mathrm{Ca}^{2+}$-water densities and the different age groups in males and females, as determined by gemstone spectral imaging. $\mathrm{P}<0.05$ vs. the ${ }^{\mathrm{a}} 20-29,{ }^{\mathrm{b}} 30-39,{ }^{\mathrm{c}} 40-49,{ }^{\mathrm{d}} 50-59,{ }^{\mathrm{e}} 60-69$ and ${ }^{\mathrm{f}} 70-79$ years groups, respectively.

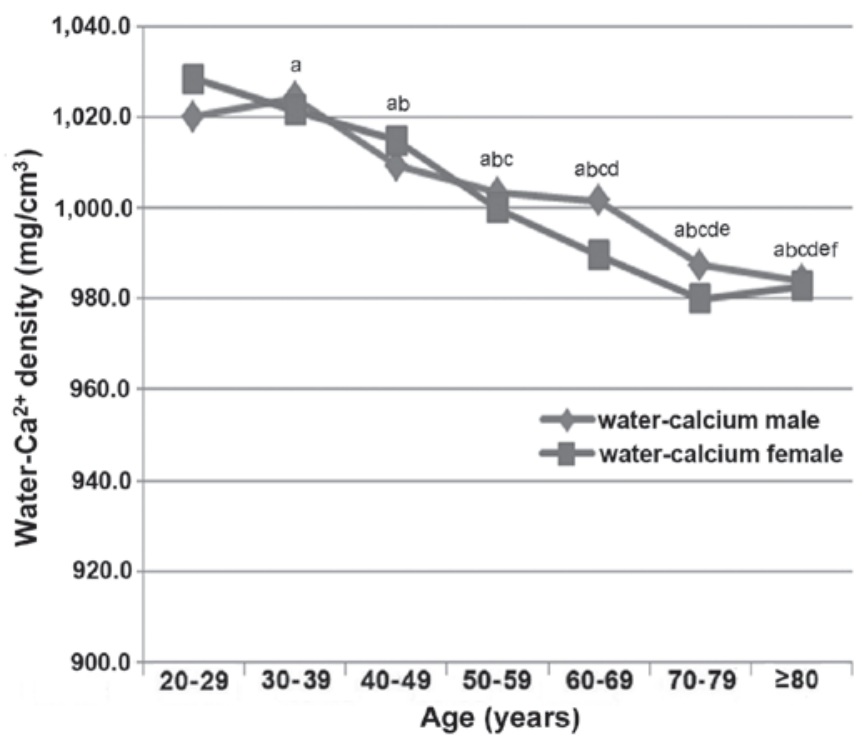

Figure 4. Correlation curves of vertebral water- $\mathrm{Ca}^{2+}$ densities and the different age groups in males and females, as determined by gemstone spectral imaging. $\mathrm{P}<0.05$ vs. the ${ }^{\mathrm{a}} 20-29,{ }^{\mathrm{b}} 30-39,{ }^{\mathrm{c}} 40-49,{ }^{\mathrm{d}} 50-59,{ }^{\mathrm{e}} 60-69$ and ${ }^{\mathrm{f}} 70-79$ years groups, respectively.

menstruation and diet may also affect the vertebral $\mathrm{Ca}^{2+}$ content in these individuals.

The present study also measured the water- $\mathrm{Ca}^{2+}$ densities of vertebral cancellous bone in different age groups using GSI. The results revealed a correlation between their peak water- $\mathrm{Ca}^{2+}$ density values and age, but no statistically significant differences were detected among the different age groups and genders; therefore, the significance remains of water- $\mathrm{Ca}^{2+}$ density remains to be further examined.

GSCT is a newly-developed method for measuring the BMD, which may also be used as the means of monitoring the BMD prior to and following treatment. When performing chest and abdominal CT examination, the GSI $\mathrm{Ca}^{2+}$-water and 
water- $\mathrm{Ca}^{2+}$ densities of the vertebral cancellous bone could be measured at the same time, without the need to re-irradiate the vertebral body, which reduces the radiation doses and additional costs (28).

The number of patients in the present study was limited and large sample analysis could not be performed, therefore reference values of GSI-determined $\mathrm{Ca}^{2+}$-water and water- $\mathrm{Ca}^{2+}$ densities of normal vertebral cancellous bone could not be obtained. In addition, the water and fat contents inside the vertebral body may affect the results. Although the water content is low inside the vertebral body, it may have a greater impact on the results when combined with vertebral fractures and bone marrow edema. Given the aforementioned limitations of the current technique compared with other methods, further investigation is required. In conclusion, GSI may be used as a novel method of measuring the vertebral adult bone mineral density.

\section{Acknowledgements}

The present study was supported by grants from the Science and Technology Development Project of Weifang (no. 201301068) and the Science and Technology Project of Weifang Municipal Health Bureau (no. 2013089).

\section{References}

1. Charles W, Slemenda C and Johnston CJ: Epidemiology of osteoporosis. In: Treatment of the Postmenopausal Woman: Basic and Clinical Aspects. Lobo RA (ed). Lippincott Williams \& Wilkins, Baltimore, pp279-285, 1999.

2. Riggs BL: The problem of osteoporosis-its prevention and treatment. In: Prevention and Treatment of Osteoporosis. Riggs BL (ed). Hogrefe \& Huber, Lewiston, N.Y., pp9-11, 1992.

3. Li Y, Lin J, Wang P, Yao X, Yu H, Zhuang H, Zhang L and Zeng Y: Effect of time factors on the mortality in brittle hip fracture. J Orthop Surg Res 9: 37, 2014.

4. Johnell $\mathrm{O}$ and Kanis JA: An estimate of the worldwide prevalence and disability associated with osteoporotic fractures. Osteoporos Int 17: 1726-1733, 2006

5. Lenchik L, Kiebzak GM and Blunt BA; International Society for Clinical Densitometry Position Development Panel and Scientific Advisory Committee: What is the role of serial bone mineral density measurements in patient management? J Clin Densitom 5 (Suppl): S29-S38, 2002.

6. Crandall C: The role of serial bone mineral density testing for osteoporosis. J Womens Health Gend Based Med 10: 887-895, 2001.

7. Lewiecki EM: Bone density measurement and assessment of fracture risk. Clin Obstet Gynecol 56: 667-676, 2013.

8. Shuler FD, Conjeski J, Kendall D and Salava J: Understanding the burden of osteoporosis and use of the World Health Organization FRAX. Orthopedics 35: 798-805, 2012.

9. Kanterewicz E, Puigoriol E, García-Barrionuevo J, del Rio L, Casellas M and Peris P; Frodos Research Group: Prevalence of vertebral fractures and minor vertebral deformities evaluated by DXA-assisted vertebral fracture assessment (VFA) in a population-based study of postmenopausal women: The FRODOS study. Osteoporos Int 25: 1455-1464, 2014.

10. Bazzocchi A, Spinnato P, Fuzzi F, Diano D, Morselli-Labate AM, Sassi C, Salizzoni E, Battista G and Guglielmi G: Vertebral fracture assessment by new dual-energy X-ray absorptiometry. Bone 50: 836-841, 2012.

11. Nickoloff EL, Feldman F and Atherton JV: Bone mineral assessment: New dual-energy CT approach. Radiology 168 $223-228,1988$
12. Zheng S, Dong Y, Miao Y, Liu A, Zhang X, Wang B, Ge Y, Liu Y and Wang S: Differentiation of osteolytic metastases and Schmorl's nodes in cancer patients using dual-energy CT: Advantage of spectral CT imaging. Eur J Radiol 83: 1216-1221, 2014.

13. Duan X, Wang J, Yu L, Leng S and McCollough CH: CT scanner $\mathrm{X}$-ray spectrum estimation from transmission measurements. Med Phys 38: 993-997, 2011

14. Writing Group for the ISCD Position Development Conference: Technical standardization for dual-energy X-ray absorptiometry. J Clin Densitom 7: 27-36, 2004.

15. Gnudi S, Sitta E and Fiumi N: Bone density and geometry in assessing hip fracture risk in post-menopausal women. Br J Radiol 80: 893-897, 2007

16. Prevention and management of osteoporosis. World Health Organ Tech Rep Ser 921: 1-164, 2003.

17. Yu EW, Bouxsein ML, Roy AE, Baldwin C, Cange A, Neer RM, Kaplan LM and Finkelstein JS: Bone loss after bariatric surgery: Discordant results between DXA and QCT bone density. J Bone Miner Res 29: 542-550, 2014.

18. Klingberg E, Lorentzon M, Göthlin J, Mellström D, Geijer M, Ohlsson C, Atkinson EJ, Khosla S, Carlsten H and Forsblad-d'Elia H: Bone microarchitecture in ankylosing spondylitis and the association with bone mineral density, fractures and syndesmophytes. Arthritis Res Ther 15: R179, 2013.

19. Bauer JS, Henning TD, Müeller D, Lu Y, Majumdar S and Link TM: Volumetric quantitative CT of the spine and hip derived from contrast-enhanced MDCT: conversion factors. AJR Am J Roentgenol 188: 1294-1301, 2007.

20. Genant HK, Lang T, Fuerst T, Pinette KV, Zhou C, Thiebaud D and Diez-Perez A: Treatment with raloxifene for 2 years increases vertebral bone mineral density as measured by volumetric quantitative computed tomography. Bone 35: 1164-1168, 2004.

21. Cann CE: Quantitative CT for determination of bone mineral density: A review. Radiology 166: 509-522, 1988.

22. Graser A, Johnson TR, Hecht EM, Becker CR, Leidecker C, Staehler M, Stief CG, Hildebrandt H, Godoy MC, Finn ME, et al: Dual-energy CT in patients suspected of having renal masses: Can virtual nonenhanced images replace true nonenhanced images? Radiology 252: 433-440, 2009.

23. Ascenti G, Siragusa C, Racchiusa S, Ielo I, Privitera G, Midili F and Mazziotti S: Stone-targeted dual-energy CT: A new diagnostic approach to urinary calculosis. AJR Am J Roentgenol 195: 953-958, 2010.

24. Zhang D, Li X and Liu B: Objective characterization of GE discovery CT750 HD scanner: Gemstone spectral imaging mode. Med Phys 38: 1178-1188, 2011.

25. Sai H, Iguchi G, Tobimatsu T, Takahashi K, Otani T, Horii K, Mano I, Nagai I, Iio H, Fujita T, et al: Novel ultrasonic bone densitometry based on two longitudinal waves: Significant correlation with pQCT measurement values and age-related changes in trabecular bone density, cortical thickness and elastic modulus of trabecular bone in a normal Japanese population. Osteoporos Int 21: 1781-1790, 2010.

26. Nindl BC, Pierce JR, Durkot MJ, Tuckow AP, Kennett MJ, Nieves JW, Cosman F, Alemany JA and Hymer WC: Relationship between growth hormone in vivo bioactivity, the insulin-like growth factor-I system and bone mineral density in young, physically fit men and women. Growth Horm IGF Res 18 439-445, 2008.

27. Krum SA and Brown M: Unraveling estrogen action in osteoporosis. Cell Cycle 7: 1348-1352, 2008.

28. Chen J, Dong Y, Ge Y and Liu YJ: Feasibility of bone density measurement based on CT gemstone spectral imaging. Zhong Guo Yi Xue Ying Xiang Ji Shuy 29: 133-137, 2013 (In Chinese). 